\title{
HIRING A DEAN IN THE PRESENCE OF AN INTERNAL CANDIDATE: THE ANALYTICAL HIERARCHY APPROACH ${ }^{1}$
}

\author{
Sarfraz A. Mian and J. Donald Herring \\ School of Business, State University of New York, Oswego, NY
}

\begin{abstract}
This paper presents a model that was employed for analyzing the decision to hire a dean for a nezvly created school of business. In using the Analytical Hierarchy Process (AHP) the model attcmpts to combine the candidates' core job-related characteristics with the contextual factors in making the selcction. It appears that in the presence of a viable internal candidate the contextual factors which flow from the matur, of the specific institution and the actual job description become even more critical in arriving at the finul hiring decision. Based on this experience, it is proposed that the use of AHP with the help of Expert Choict software provides a viable tool for selection committees in synthesizing both objective data and subjectiv' measures in complex multi-criteria hiring decisions such as this.
\end{abstract}

Keywords: Academic hiring, multi-criteria decision-making, Analytical Hierarchy Process.

\section{INTRODUCTION}

An appropriate match between employee qualifications and job demands in today's fast changing academic environment frequently poses challenges for the search committees entrusted to aid in the hiring of key academic officials such as the dean. What is clear to all is that the quality of such choices often affects the organization for decades [1], and the successful selection and then hiring of such candidates entail complex decision making processes. What is less clear is how: schools might use multiple criteria to arrive at decisions which not only reconcile differences among conflicting objectives but also factor in various organizational and personality specific realities. One such challenge is the hiring decision made in an environment in which a qualified internal candidate is being considered. This situation warrants not only multiple considerations but also focuses on marginal differences and comparisons among the candidates with dissinilar qualifications especially with respect to the internal candidate. These decisions involve trade-off:and intuitive judgements combined with the objective data, often carried out in group decisionmaking settings.

Recently, at SUNY-Oswego's new Business School, there was a dean selection situation in which the internal candidate was the Interim Dean and former Department Chair. The selection committee with the support of the School faculty was seeking a candidate who could provide the best fit in terms of facing the external as well as internal challenges to the newly created School of Business. This warranted a thorough analysis of each candidate's background and qualifications $m$ light of these challenges.

In this paper an attempt will be made to illustrate how this decision situation was analyzed via Analytical Hierarchy Process (AHP) -- a multi-criteria decision making technique [2]. By using $\mathrm{AHP}$, the decision problem is delineated into a hierarchy in the form of a goal, criteria, and

1. Copyright (e)1994 by S.A. Mian and J.D. Herring. 
alternatives. This allows pairwise comparisons of the hierarchical elements, enabling the decision maker(s) to enter verbal/numerical judgements with the help of Expert Choice software [3]. The judgements are further synthesized to provide a ranking of the altematives for the best choice. A further refinement of these decisions is provided by the sensitivity analysis showing how changes in assigning relative priorities in judgements may alter the decision. This exercise provided a clea: insight, there by facilitating the selection process and final hiring of the dean.

\section{THE DEAN HIRING DECISION MODEL}

In the literature several authors have proposed the use of AHP in personnel selection [5,9]. A basic objective of personnel selection is to separate, from a pool of applicants for a job, those that have the appropriate knowledge, skills, and abilities (KSAs) to perform well on the job [4]. In order to hire the proper person to fill the dean's position, it was first necessary to identify the key areas of evaluation and then the specific traits to which these areas contribute. Therefore, essentially, there are two broad areas of analysis: first, the selection process which entails collecting and evaluating information about a pool of applicants in order to qualify them for employment; second, ranking of the qualified candidates and finally the hiring decision which takes into consideration the contextual and other personality "fit" factors.

The information for selecting a pool of qualified dean candidates from the list of applicants came from various sources including application forms, telephone interviews, and letters of recommendation. This resulted in a pool of three external candidates and one internal candidate. The offer of employment was to be given out of this pool of selected "qualified candidates" based on the best "fit". It is this second part which is the focus of this analysis.

Based on the AHP approach a hierarchical model is developed as shown in figure 1 [5] which delineates various elements of the hierarchy. Under the obvious goal to "hire the best dean

\section{Fig 1: The Dean Hiring Decision Model}

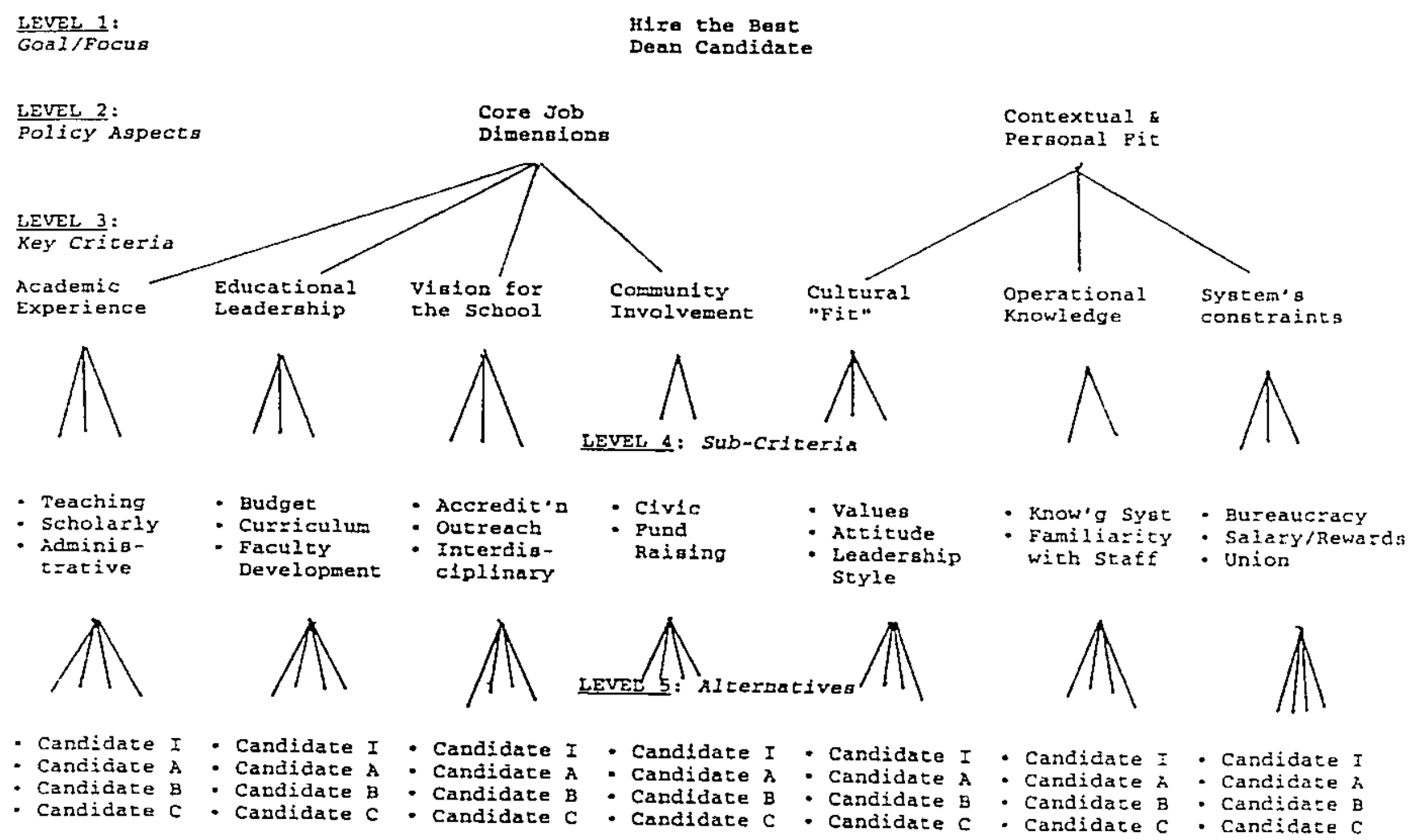


candidate" there are two sets of decision criteria titled "policy aspects" which are: core job dimensions and contextual and personal "fit" factors. shown in the figure. The core job dimensions include the most obvious characteristics of good deans, such as academic experience, educational leadership, vision, and community involvement. The contextual and personal fit factors include fit with the organizational culture, operational knowledge, and the system's constraints. Each of these sets of criteria are defined by multiple sub-criteria as shown in the figure. In using this model all job candidates are listed as alternatives in the model at the bottom level.

One of the critical aspects of the model in figure 1 is the weighting of the selection criteria. This can be performed by combining the objective data with the intuition, experience, and judgement of the search committee members. Since establishing relative importance of specific criteria differs according to the decision maker's perceptions of a particular situation and the boundaries of his/her own background, methods which seek to enhance various decision making processes during the ranking of candidates must be able to process not only objective data but also subjective judgments and uncertain information. Further, they must be adaptable to the specifics of the organization and carried out in group settings.

In this particular case, decisions to trade knowledge for skills, skills for abilities, or abilities for contextual familiarity, as well as other intangible trade-offs were common, it was decided to communicate and clearly define various criteria used in this model.

\section{DEFINITIONS OF THE DECISION CRITERIA EMPLOYED}

Once the key criteria used by the selection committee in candidate evaluations had been identified, definitions of these terms were developed. The technique of brainstorming was utilized, with the submitted applications and other supporting material analyzed for key descriptors or words used to express a term's meaning. The following definitions were then written for the seven criteria and their sub-criteria mentioned earlier (figure 1):

(1) Academic Experience: basic requirement in the scholarship area was a terminal degree in a business related area - preferably from an AACSB accredited program. Beyond this basic requirement, all candidates were expected to show activity in conference presentations and publications in professional journals. Consulting experience was considered a plus. The administrative experience (not necessarily in higher education only) would include successful experience as a Departmental Chair, Assistant Dean, or Associate Dean. Some candidates also had credentials of Provost and small college President. Previous college teaching experience was preferred in that it would show a successful performance in a school setting. This would not, however, be a mandatory credential.

(2) Educational Leadership: budget development and operation is a most important area for the dean's position which places the operation in the context of the entire university. It is in this area that scarce resources are allocated. A new school needs someone who evidenced skill in the total financial area. Curriculum development although very important for a new school was slightly less weighted than fiscal ability. It is necessary for the dean to provide leadership for curriculum change, but not necessarily to "do it." Faculty development skills were desired in as much as it was intended that the School would grow slowly in the near future and the assimilation of new faculty members would be necessary. Also, the current faculty needed to be developed to move from a primarily teaching emphasis to a teaching, cum research emphasis.

(3) Vision for the School: one of the desired skills of the new dean was experience with the AACSB accreditation process. It was intended that as rapidly as possible the new Oswego school of business would pursue such accreditation. This became a major criterion in shortening the original candidates list. As a Department of Business Administration within the Professional Studies 


\section{S.A. Mian \& J.D. Herring / Hiring New Dean - AHP Approach}

Division there was little time for cultivating the area business community and this activity was not highly valued. However, as a School of Business it was made a priority concern. Skill in cultivating relationships with area industries and businesses was very important in the dean selection. In as much as Oswego is both a new and relatively small School of Business it was determined that future growth in programs and other curriculum options would come from interdisciplinary endeavors. On the horizon were such possibilities as a technology and environmental management program, and an arts management program. All of these, were by necessity interdisciplinary.

(4) Community Involvement: one of the areas of concern for the new School of Business was to become more civic minded. This would present the School as a partner with other local businesses and industries. It was desired that the dean candidate show a pattern of civic activities such as memberships in Rotary. Kiwanis, Chamber of Commerce and other volunteer community activities. It had also been determined that new funds from State sources would probably not be forthcoming. So it was necessary for the new dean to possess fund raising skills if the School was to grow. A proven track record in various fund raising activities was searched for. Candidates who were successful grant writers were preferred.

(5) Cultural Fit: this whole area was of greater concern to the faculty and the Search Committee than to administration. It was intended that the successful candidate not change significantly the organizational culture (or climate) of the School. This was perhaps the single most important aspect of the search. It was desired that the candidate exhibit a leadership style that was "open" and collegial. The School had in its development a history of cooperation and closeness among staff members that included both professional and social activities. It was of the highest priority for staff that this continue. This area was also the most difficult to ascertain, little information was provided in the resume or letters of recommendations. Candidates with well developed interviewing skills could tell the committee what they "wished to hear." Judgements in the area were based in part on the candidates social functioning during the total campus visit. It was a prime concern that the new dean exhibit and value an integrated style of management. That is a style that combined the task concerns of the School with the relationships and climate activities that were ongoing. The candidate's ability to integrate tasks and relationships to motivate, to develop, to trust, to listen, to encourage and to support in both individual and group settings was a must [6]. Not being threatened by emergent leadership activities by members of the staff and the attitude of "openness in climate and in communication" to all was also a prime consideration [7].

(6) Operational Knowledge: in as much as Oswego is part of the State University of New York, a large bureaucratic system, the successful candidate should be able to not only tolerate bureaucratic functioning but be able to thrive in that system. The ability to do both that and have the ability mentioned in cultural fit required a successful candidate considerable style flexibility. The knowledge of the system and how to be successful within it was mandatory. The new dean if he or she were to continue the activities of the School, as well as leading to new activities needed to have a familiarity with the current staff. Little promise of staff turnover or additions was seen. A dean who might take several years to get comfortable with staff was not highly prized. Knowing the strengths and weaknesses of current staff members would aid the successful candidate greatly.

(7) System Constraints: being able to lead in a bureaucratic context was a constraint on the candidates. Candidates who had been successful in business or in small liberal arts schools might have difficulty in finding their way through the morass of a large bureaucracy. As has been previously stated the comfortableness, the ability to function with rules and regulations, and the time constraints imposed by the system was a problem for the successful candidates. The selection 
process was further constrained by the salary range proposed for the new dean. This salary while "competitive" was somewhat below the "norm" for deans in similar sized schools. The faculty of the School are all members of an agency shop work place. The flexibility of operations normally found in non-union work settings is not available in this situation. The ability to work smoothly with a negotiated contract, governance procedures, and unchanging reward system were also mandatory.

Of the various decision elements which have been identified and then defined in this typical dean's hiring situation are analyzed further to illustrate the use of this AHP-based model with the help of Expert Choice software.

\section{ANALYSIS OF THE DECISION MODEL USING EXPERT CHOICE SOFTWARE}

Based on the AHP model for hiring the new dean described above (figure 1), a microcomputer based model is constructed using Expert Choice software [3]. The goal, criteria, sub-criteria, and alternatives are delineated in a hierarchical fashion on a microcomputer screen as shown in figure 2. More detailed microcomputer screen views at various levels of the model under one key decision factor (core job dimensions) are depicted in figures 3 to 5. Similar computer screen views can be shown under the second key decision (contextual and personal fit) factor.

After the computer model is completed, starting from the top of the hierarchy (level 1) it was necessary to compare the two key policy considerations (level 2) in a pairwise fashion and enter the decision makers relative priorities by entering their judgements, as shown in figure 6 (graphical mode, which is particularly useful when there is not much redundancy involved such as in case of only two factors). From level 2 below focusing on core job dimensions (and later on under contextual and personal fit factors) various criteria (level 3) are compared in a pairwise fashion as shown in figure 7 (verbal mode, using a Likert scale), and figure 8 (numeric mode, showing the judgement matrix on a scale of 1 to 9).

\section{Fig 2: Complete Model Wrth Glossary}

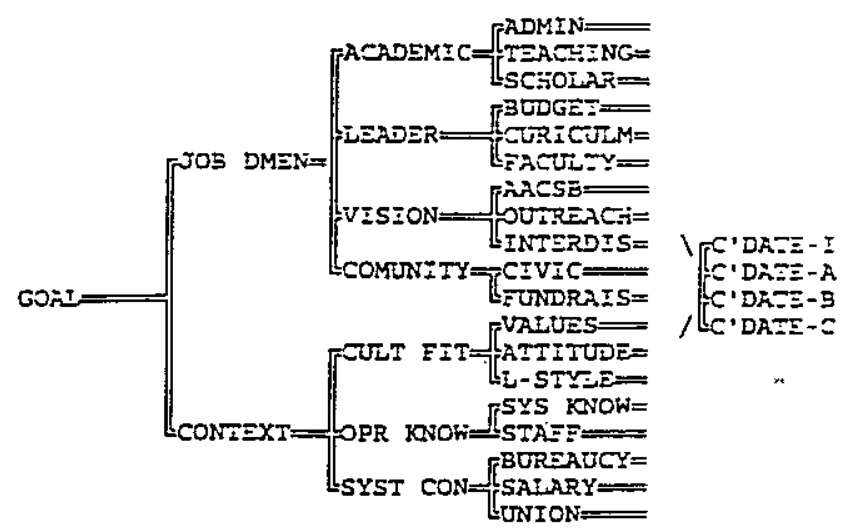

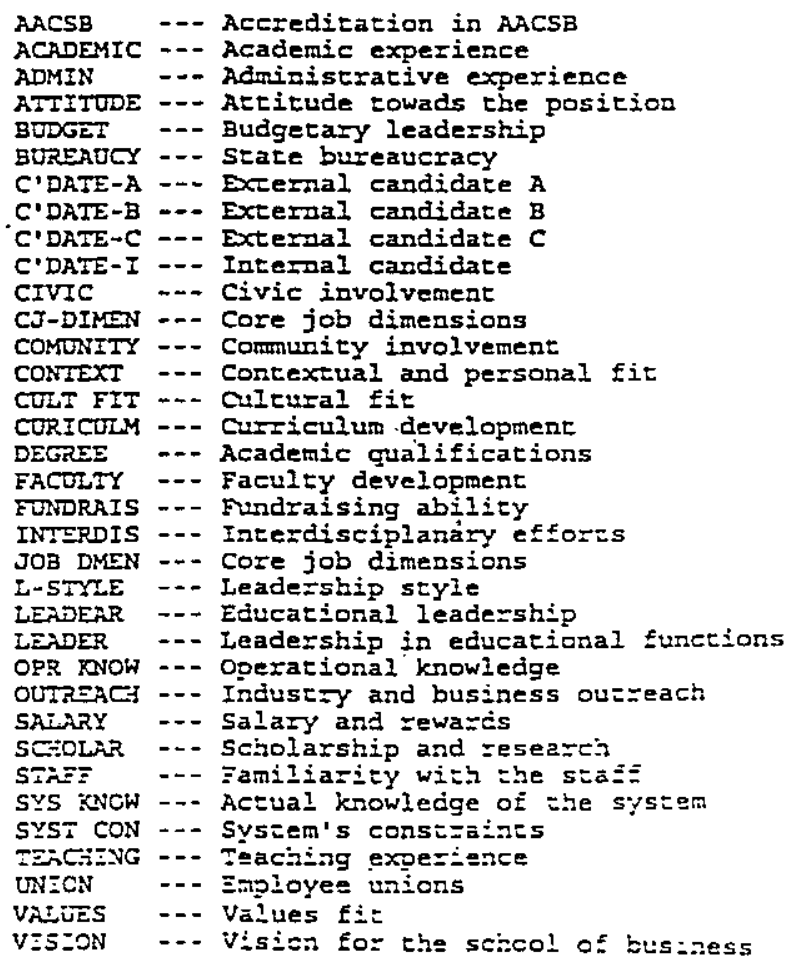



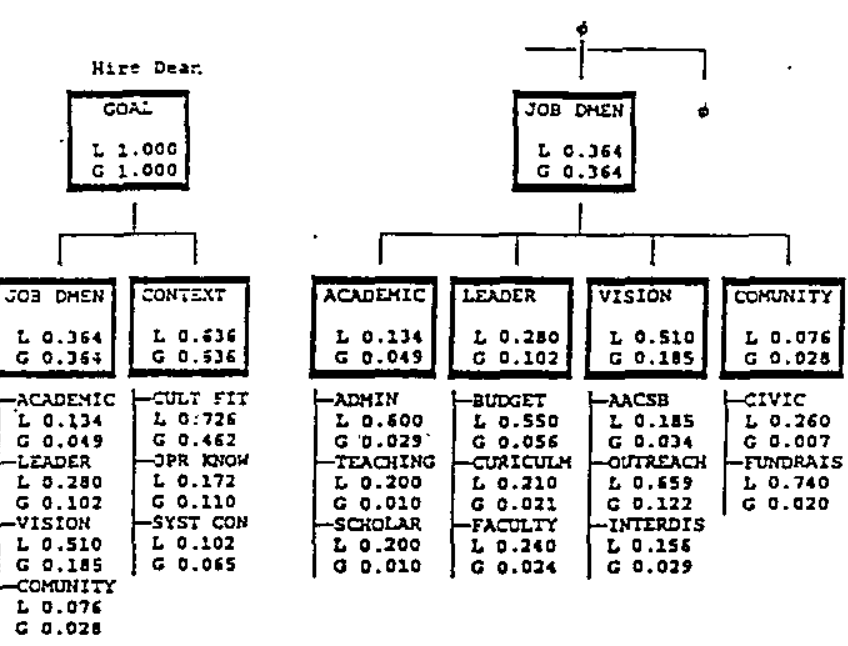

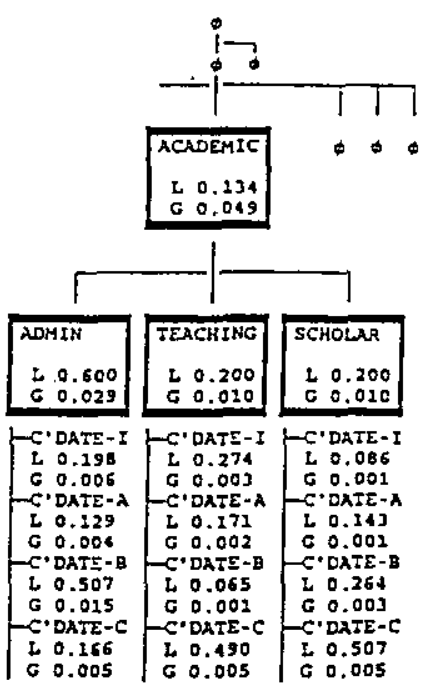

Fig 6: Graphic Pairwise Comparison

COnLt $H \$ x=0, \pi)$

corrext ... Sontextual and pereonal $21 \mathrm{t}$

JOU DOEEN... Core job dimeneions

0.151

mRoRitiss

$308 \mathrm{Dan}$

CONTEXT

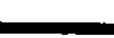

IMCONSIBTENCY MATSO $=0.000$.

Similarly, from level 3 below focusing each criteria and various sub-criteria (level 4) are assigned relative importance.

Likewise, pairwise comparisons are carried out for each of the candidates and judgements are entered into the computer (using any one of the modes described earlier). This procedure is repeated under each sub-criteria keeping in view the goal. A synthesis which details all the judgements is , shown in figure 9. Figure 9 shows that the sum of the assigned weights (local) at each level equals one. Results of the synthesis is shown in figure 10, which rank orders the dean candidates. The analysis shows to the decision maker(s) that candidate $I$ is preferred, followed by candidates A, B and then $C$.
Fig 7: Verbal Pairuise Comparison W1th respect to
JOS DMEN $<$ CONi

traogx : beadershlp in educational tunctions

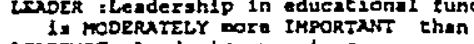

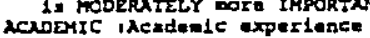

VERT TTRONG -......

STRONG-...........

Hoverate-2...... 2

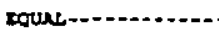

Fg Q: Numeric Paimiso Comparison

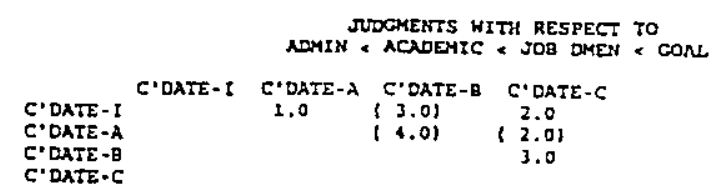

Matrix unery indicaten "shat now slement is

1 EOUALLY 3 MODERATELY 5 STROHGLY 7 ' JERY STRONGLY 9 EXTREMEL:

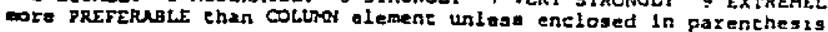


Fig 9: Synthesis Showing Details

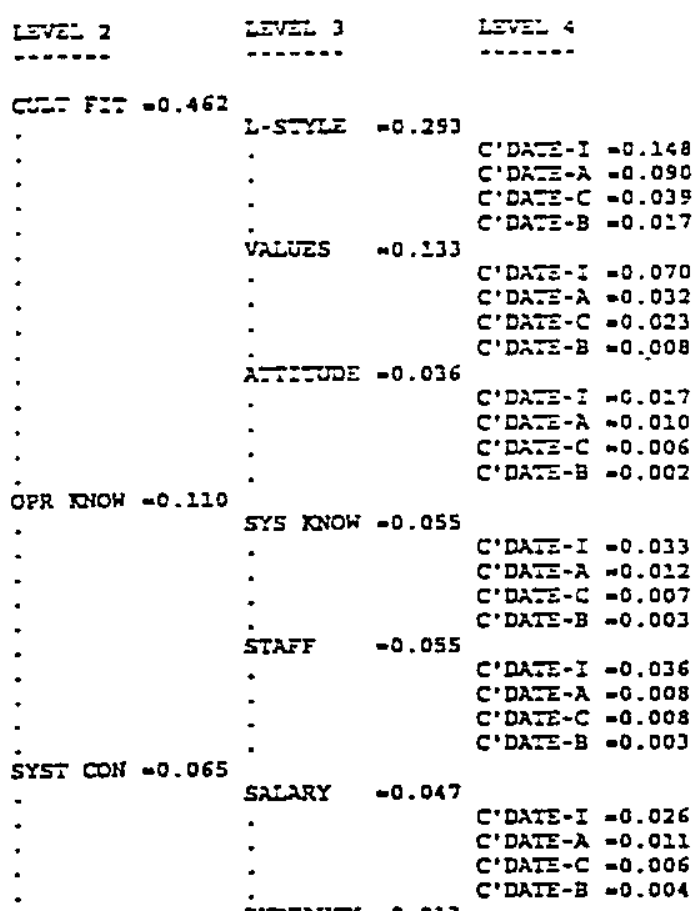

gergauCr $=0.013$

$=0.006$

$c \cdot D A F=-I=0.007$ C'DAIE-A $=0.003$ C.DATE-C =0.002 C'DATE-z $=0.001$ ONION $\quad-0.006$

DATE-3 $=0.001$

c+DA:E-E=0.003

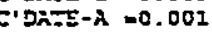
C'DRㅡㄹ-C.74E-03 C'DATE-3.34E-03

JOP DMEN $=0.364$

OTREACT $=0.222$

$$
\text { . }
$$

ixcs 3

22053 -0.334

C.2A.E-z -0.071 c. c. $2 x=5-n=0.021$ C'गमाE-: $=0.008$

C.DATE-C $=0.016$

C.DATE-B $=0.020$ C'DXTz-A $=0.005$ C'DATE-I $=0.003$

IXTEROIS $=0.029$

C.DATE-T $=0.023$ C'DATE-B $=0.008$ C.DATE-C $=0.006$ C.DATE-A $=0.004$ LEDER $\quad-0.102$ BODEe: -0.056

C.DATE-B $=0.022$ C.DATE-I $=0.023$ c'DATE-2 $=0.031$ C'DATE-C =0.009

Facoler 0.024

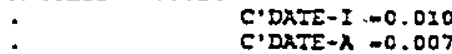
C.DATE-C =0.005 $C \cdot D A T E-B=0.003$

CORICULA -0.02I

C.DRTE-I $=0.008$ C.DATE- $=0.008$ C.DATE-A $=0.008$

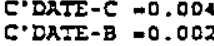

ACADEMTC $=0.049$ ADMIN $=0.029$

C'DATE-B $=0.025$ C'DATE-I $=0.006$ C.DATE-C $=0.005$ C'DATE-2 $=0.004$

ierciris $=0.020$

C'DATE-C $=0.005$. c. DA.E-I $=0.003$ C. DגटE-A $=0.002$ C' गגE-B.63E-03

schoiver -0.020

$$
\begin{aligned}
& \text { c'Da-E-c }=0.005 \\
& \text { C'כRTE-B }=0.00 \mathrm{~J} \\
& \text { C. כरू:-A }=0.00
\end{aligned}
$$

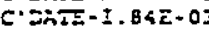

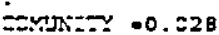

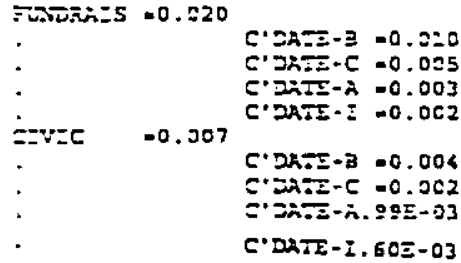


Fig 10: Synthesis for Hiring Dean

Synthesis of Leaf Nodes with respect to GOAI DISTRIBUTIVE MODE

OVERALL INCONSISTENCY INDEX $=0.04$

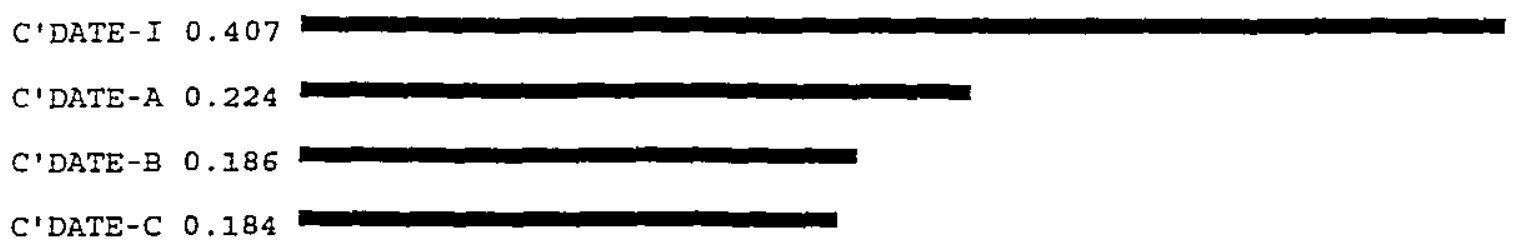

C'DATE-A -- External candidate $A$

C'DATE-B -. External candidate B

C'DATE-C -- External candidate $C$

C'DATE-I -.. Internal candidate

\section{DISCUSSION}

In this exercise AHP approach appears to have facilitated the process of group decision making by removing the communication barriers (through structuring the problem) and helping to keep the focus around objectives rather than alternatives [8]. Therefore, there was no need for the individual committee members to resort to common simplistic decision strategies (such as based on one's gut feelings) in the presence of a multitude of information and conflicting objectives. Because the discussion was structured, addressing each facet of the decision in turn, the members were guaranteed the opportunity to contribute their expertise. Judgements were based on hard data, interviews and meetings with the candidates, as well as general knowledge and experience of each committee member. Instead of drifting from topic to topic, the committee progressed smoothly toward a resolution of the decision as the hierarchy was agreed to and ratio scale priorities were developed for each aspect of the decision. The sensitivity analysis provided answers to a number of 'what if' questions posed by various members.

The fact that there was a viable internal candidate who offered contextual experience and time tested personality fit, qualifications which none of the external candidates possessed, was a strong plus factor for that candidate. It is also true that some of the external candidates offered varied leadership experience and possibly a new vision to the School which internal candidate did not offer. Due to the specific internal challenges posed by the system the committee was poised towards assigning a much higher priority on the contextual and personality fit factors as would have been the case had no viable internal candidate been present (figure 11). These considerations posed challenging trade-offs for the committee. Consequently, results of the above analysis show that the priorities of the external candidates $A, B$ and $C$ are quite close, and the decision maker could then think of other objectives that he/she would hope to achieve in accepting the different candidates and will then incorporate these as additional factors in the model. Also, the decision maker might contemplate the likelihood of changes in circumstances in which candidate $I$ is not available. This may well change the relative importance of some of the criteria. Figure 11 shows how. well each of the four alternative candidates "perform" on each of the major criteria, as well as their overall priorities. 
The sensitivity of the alternative priorities to changes in the importance of criteria (or subcriteria) can also be investigated with the software's sensitivity display, shown in figures 12 for the level 2 policy aspects criteria. (The current relative priority of the criteria is shown in figure 11 , represented by the bars shown on the left). If the decision maker(s) would like to know what the relative preference of the alternative would be if the importance of contextual fit became less important i.e., moving the context line to the left; it is clear that candidate I does become less preferable. The software provides a dynamic way to investigate the effect of potential changes in the relative priority inputs as shown in moving from figure 11 to 12 . Here, by increasing or decreasing the assigned weight (represented by the length of the bar) of a criteria would accordingly affect the priority of the alternative most affected by the criteria.
Fig 11: Dynamic Sensitivity Analysis

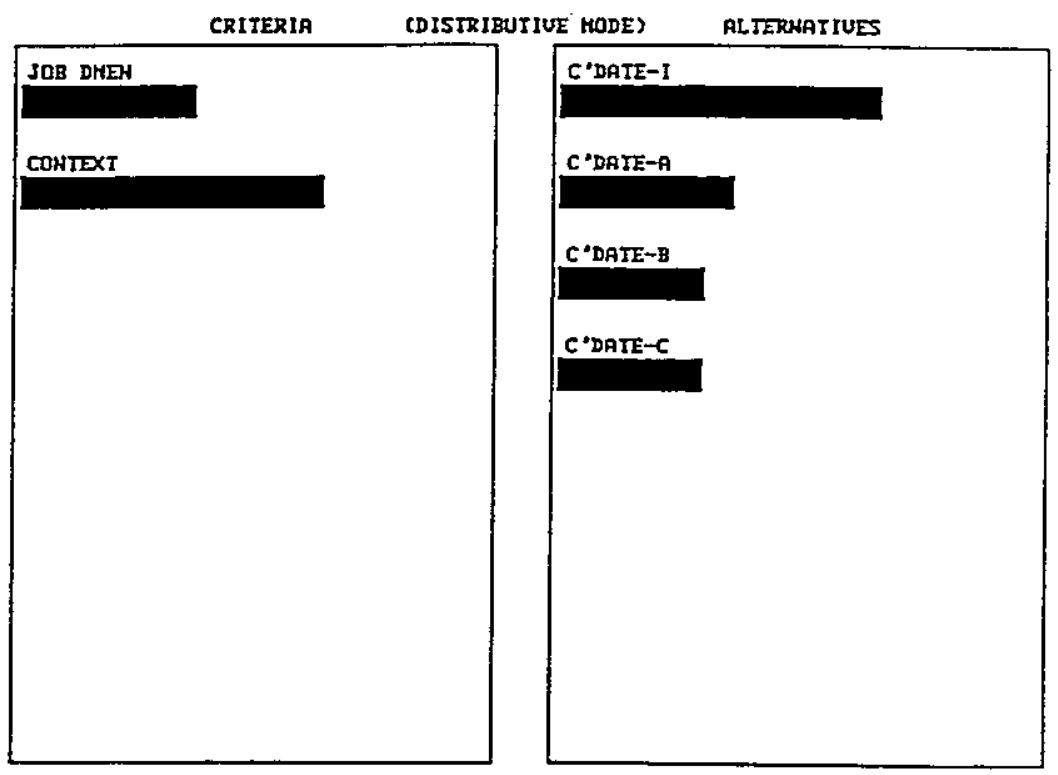

Fig 12: Decreasing the Importance of Contextual Factors

CRITERIA (DISTRIBUTIUE HODE) ALTERNATIUES

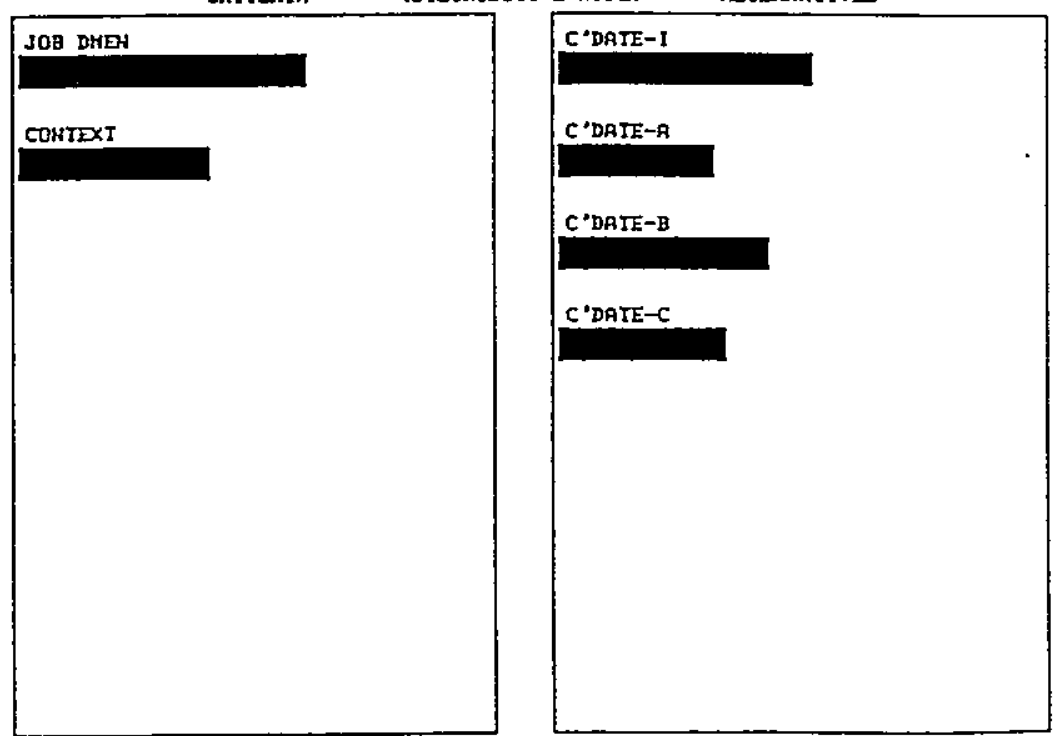




\section{CONCLUSION}

The discussion presented above illustrates how the Analytical Hierarchy Process with the help of Expert Choice software was effectively used to analyze complex multi-criteria decision encountered during the dean hiring process at SUNY-Oswego. The process takes into consideration both objective as well as subjective measures, and provides an easy to use tool for selection committees and college/university administrators in analyzing such complex decisions.

\section{REFERENCES}

[1] Milkovich, G. \& Boudreau, J. (1988) Personnel Human Resources Management: A Diagnostic Approach, Texas Business Publications, TX., pp 398-399.

[2] Saaty,T., The Analytical Hierarchy Process, McGraw Hill, N.Y., 1980.

[3] Forman, E., et al, Expert Choice, Decision Support Software Inc., VA., 1983

[4] Gatewood, R. \& Feild, H. Human Resource Selection, Dryden Press, NY, 1994, PP 381-415.

[5] Saaty, T., Decision Making for Leaders, Wardsworth Inc., Belmont, CA., 1982.

[6] Hughes, R. et al, Leadership: Enhancing the Lessons of Experience, Irwin, Homewood, IL, 1993, pp 165-182.

[7] Vroom, V. \& Jago, A. The New Leadership: Managing Participation in Organizations, Prentice Hall, NJ., 1988.

[8] Dyer, R. \& Forman, E. "Group Decision Support with the Analytical Process," Decision Support Systems, Elsevier, North-Holland, No. 8, 1992, pp 99-124.

[9] Wells, W. \& Mian, S. "Use of Analytical Hierarchy Process in Project Management Decisions", Management of Technology II, Editors, Khalil and Bayrakhtar, Institute of Industrial Engineering, Norcross, GA., 1990.

\section{BIOGRAPHICAL NOTES}

Sarfraz A. Mian, is an Assistant Professor of Management at the School of Business at SUNY-Oswego. Dr. Mian earned his MS from Northwestern University and an MBA and Ph.D. from George Washington University. Prior to his current position he has taught strategic management at University of Maryland and has 12 years of business/industrial management experience. He has presented papers and written articles on strategic management, and dccision making.

J. Donald Herring is a Professor of Human Resource Management at the School of Business at SUNYOswego. Dr. Herring earned his MS and Ph.D. from Syracuse University. He is a member of numerous professional and civic organizations and has recently been elected as Chairman of the national College Relations Committee of the Society for Human Resource Management. He has presented papers and written articles on human resource management, and leadership. 